\title{
LINGUAGENS DA ARTE E CRIANÇAS PEQUENAS: UMA LEITURA DA PRODUÇÃO DA ANPED (2007-2011)
}

\author{
ARTISTIC LANGUAGES AND SMALL CHILDREN: A READING \\ OF ARTICLES PRESENTED TO THE NATIONAL ASSOCIATION \\ FOR GRADUATE STUDIES IN EDUCATION - ANPED (2007-2011)
}

\section{LENGUAJES DEL ARTE Y NIÑOS: UNA LECTURA DE LA PRODUCCIÓN DE ANPED (2007-2011)}

\begin{abstract}
Alessandra Mara Rotta de Oliveira ${ }^{1}$
Universidade Federal de Santa Catarina, Departamento de Metodologia de Ensino, Professora Adjunta III no Centro de Ciências da Educação; Pesquisadora com ênfase nas temáticas arte, imaginação, práticas pedagógicas na educação infantil e formação de professores
\end{abstract}

Resumo: O presente artigo é resultado de uma investigação de cunho documental sobre a produção acadêmica presente nas reuniões anuais da Associação Nacional de Pós-graduação e Pesquisa em Educação (Anped) no GT 24, Educação e arte, e no GT 07, Educação de crianças de 0 a 6 anos, no período entre 2007 e 2011. O objetivo principal foi realizar o mapeamento e a análise qualitativa e interpretativa da produção voltada à educação das crianças de 0 a 3 anos de idade e as linguagens da arte. Os resultados apontam para a ausência de trabalhos específicos ao recorte do mapeamento. Assim, entre outros aspectos, indica-se a necessidade do fortalecimento do diálogo entre o GT 24 e o 07 na Anped e a averiguação em outros espaços de notório reconhecimento científico sobre a presença ou não de uma produção acadêmica voltada à temática em questão.

Palavras-chave: Linguagens da arte. Crianças pequenas. Educação Infantil.

Abstract: This article is the result of an investigation of scholarly articles presented at the annual meetings of the National Association of Graduate Studies in Education (Anped) from the years 2007 to 2011 to Working Group 24, Education and Art and

\footnotetext{
${ }^{1}$ Pós-doutora pela Università Degli Studi di Firenze (2015-2016), tendo como foco o Teatro para crianças de 0 a 3 anos de idade e a Pedagogia da Infância; Doutora em Educação pela Universidade Federal de Santa Catarina, com Doutorado Sanduíche na Universitá Cattolica del Sacro Cuore (Milão, Itália, 2006-2007), tendo como tema investigativo a linguagem da escultura e a imaginação entre as crianças pequenas.
} 
Working Group 7, Early Education for Children from 0 to 6 years old. The main objective was to conduct a mapping and qualitative and interpretive analysis of articles focusing on the education of children from 0 to 3 years old and artistic languages. The study found an absence of specific studies about this issue. This indicates the need to strengthen the dialog between these two working groups at Anped and to look for articles about this issue in other recognized spaces of academic publications.

Keywords: Artistic languages. Small children. Early childhood education.

Resumen: El presente artículo es el resultado de una investigación documental sobre la producción académica presente en las reuniones anuales de Anped en el GT 24, Educación y arte, y en el GT 07, Educación de niños de 0 a 6 años, en el período entre 2007 y 2011, y cuyo objetivo principal es mapear y analizar de manera cualitativa e interpretativa la producción direccionada a la educación de niños de 0 a 3 años y los lenguajes del arte. Los resultados señalan la ausencia de trabajos especificos para el corte anunciado. De esa forma, se indica la necesidad de fortalecer el diálogo entre el GT 24 y el GT 07 en Anped y averiguar, en otros espacios de reconocimiento científico notable, la presencia o ausencia de una producción académica direccionada al tema en cuestión.

Palabras clave: Lenguajes del arte. Niños. Educación Infantil.

\section{INTRODUÇÃ̃O}

Nos últimos anos, vivemos, sem dúvida, uma expansão da Educação Infantil (creche 0 a 3 anos, pré-escola 4 a 5 anos) em território nacional. Tal expansão expressa as lutas dos movimentos sociais em prol da Educação Infantil, as transformações no mundo do trabalho e da economia, das políticas públicas e do direito, assim como o desenvolvimento de novas percepções sobre as crianças e suas infâncias nas áreas da Sociologia, da Psicologia, da Educação, da Arte e da Cultura, especialmente no que se refere às crianças de 0 a 5 anos de idade. Ao mesmo tempo, não podemos negar as profundas ligações entre essa ampliação da rede de Educação Infantil nacional com as pressões políticas internacionais que, como bem pontua Ferreira (2016, p. 2), pouco questionam a qualidade da educação construída e ofertada para as crianças e suas famílias nesse processo de alargamento.

Sob a pressão dos organismos internacionais tivemos, no ano 2009, a aprovação da Emenda Constitucional n. 59 (BRASIL, 2009), que determina a obrigatoriedade da Educação infantil para as crianças de 4 e 5 anos de idade (pré-escola). Nesse 
contexto que legalmente prioriza a Educação Infantil a partir dos 4 anos de idade, a educação formal das crianças de 0 a 3 anos de idade (crianças pequenas) acaba, segundo Ferreira (2016) e Campos (2015), sendo sustentada por estratégias que abarcam o atendimento parcial dessa faixa etária. Ao mesmo tempo, tal movimento acaba por fortalecer os convênios com objetivos voltados a atingir as metas de universalização da Educação Básica com um "padrão básico de atendimento." (FERREIRA, 2016, p. 9). Esse padrão desconsidera muitas das conquistas políticas e sociais, assim como as educativas e pedagógicas em relação à Educação Infantil (ROCHA, 2001).

Diante dessa realidade, cabe dizer que, hoje, não se trata somente de garantir contextos socioeducativos às crianças de 0 a 3 anos de idade, mas, igualmente, de lhes assegurar processos formativos em instituições públicas de Educação Infantil e de gestão pública pautados, entre outros aspectos: na Convenção sobre os Direitos das Crianças (NAÇÕES UNIDAS, 1989); na compreensão das crianças, desde a mais tenra idade, como atores sociais, produtoras de culturas infantis (SARMENTO, 2004; CORSARO, 2002; COUTINHO, 2010), que se expressam e compreendem o mundo por meio de múltiplas linguagens; na Pedagogia da Infância (ROCHA, 2001; BARBOSA, 2010); e na Carta dos direitos das crianças à arte e à cultura (LA BARACCA - TESTONI RAGAZZI, 2011).

Na direção de uma Educação Infantil comprometida com a qualidade pedagógica, faz-se necessário não somente assegurar o ingresso e o acolhimento (STACCIOLI, 2013) das crianças pequenas nas creches e pré-escolas, mas conhecer seus modos de criação e fruição nas linguagens da arte e, simultaneamente, edificar contextos favoráveis aos seus encontros com a produção artística profissional de qualidade a elas destinada.

Certamente, para a construção, a expansão e o fortalecimento de práticas pedagógicas e, com elas, a atuação das(os) professoras(es) na formação das crianças de 0 a 3 anos de idade, que abarquem e desenvolvam - com as próprias crianças e no diálogo com suas famílias - práticas relacionadas à arte e suas linguagens, faz-se necessário mapear ou dar a conhecer os possíveis pressupostos teóricos e mesmo artísticos que podem colaborar para com a construção de propostas e ações. ${ }^{22}$ Tal prer-

\footnotetext{
${ }^{2}$ Somos cientes de que, para uma atuação qualificada dos professores com as crianças nas instituições de Educação Infantil, não basta que estes tenham acesso à produção científica de qualidade. Defendemos que, com esse acesso, tenhamos a garantia de processos de formação inicial e continuada para os professores - esta última, de forma sistemática entrelaçando as mais diversas dimensões da educação das crianças em creches e pré-escolas -, planos de carreira e salários dignos, bibliotecas atualizadas e acessíveis aos professores, ampliação constante dos repertórios artístico-culturais desses profissionais, assim como um adequado processo de acompanhamento, construção e reflexão sobre as práticas e a documentação pedagógica engendradas cotidianamente nas creches e pré-escolas.
} 
rogativa faz emergir as seguintes indagações: quais são as temáticas investigativas mais recorrentes na produção acadêmica no campo da Educação quando o recorte se refere às linguagens da arte e a educação das crianças pequenas? Quais são os autores, as principais fontes teóricas que sustentam tais investigações? Que contribuições teórico-metodológicas essas pesquisas apontam para a construção de práticas pedagógicas voltadas à arte e suas linguagens entre as crianças de 0 a 3 anos de idade nas instituições de Educação Infantil?

Apresentamos, como resultado parcial do estudo, reflexões tecidas a partir de uma pesquisa documental (CELLARD, 2012) realizada no campo da Educação, tendo como base a produção acadêmica que compõe os anais das reuniões nacionais da Associação Nacional de Pós-Graduação e Pesquisa em Educação (Anped) (20072011), com recorte no Grupo de Trabalho Educação e Arte (GT-24) e no Grupo de Trabalho Educação de crianças de 0 a 6 anos (GT 07), tendo como objetivo geral o mapeamento e a análise qualitativa e interpretativa da produção voltada à educação $\mathrm{da}(\mathrm{s})$ criança(s) pequena(s) com o recorte das linguagens da arte.

\section{GUIAS PARA UMA LEITURA}

Um estudo que interroga pelos pressupostos teórico-metodológicos que sustentam ou que venham a sustentar as práticas pedagógicas desenvolvidas no contexto da educação formal das crianças pequenas com foco nas linguagens da arte requer a delimitação de conceitos centrais à compreensão da proposta. Tal delimitação nos permite construir um caminho investigativo e interpretativo que não nega a pluralidade e a complexidade das linguagens artísticas e da área da Educação Infantil, em especial, da educação das crianças de 0 a 3 anos de idade, mas que, exatamente pela complexidade e amplitude da temática, exige recortes a fim de não cairmos em um abismo conceitual e prático.

Começamos por demarcar nossa compreensão de prática pedagógica. Toda prática pedagógica é histórica, cultural, social e politicamente situada, guiada por objetivos, conhecimentos e valores consubstanciados na ação docente planejada (intencional), sustentada na relação entre teoria e prática no campo da Educação. As práticas pedagógicas abarcam, instauram e são instauradas em dinâmicas de socialização, propagação e apropriação de conhecimentos historicamente produzidos e sistematizados (local e globalmente) em espaços-tempos concretos nos quais distintos sujeitos e classes sociais atuam. Envolvendo diferentes sujeitos em processos interativos, as práticas pedagógicas abrem possibilidades para a expansão e a criação 
de novos conhecimentos. Isso porque compreendemos que todo sujeito ativo nesse processo possui condições de estruturar e manifestar diferentes formas de atuar no mundo, sentir, pensar, interpretar e mesmo criar realidades sociais, culturais, políticas e artísticas diversas (BARBOSA, 2010a; ROCHA, 2001), que, assim, acabam por constituir o próprio sujeito que nelas atua.

Falar em prática pedagógica na educação das crianças de 0 a 3 anos de idade não é uma tarefa simples, uma vez que estudiosos e pesquisadores da área da Educação Infantil têm, historicamente, buscado afirmar o caráter pedagógico do trabalho realizado com as crianças nas creches (TRISTÃO, 2004; SCHMITT, 2008; COUTINHO, 2010; FOCCHI, 2013), pois este se diferencia do trabalho pedagógico que corporifica e identifica a educação da infância nas séries iniciais do Ensino Fundamental. ${ }^{33}$ Toda prática pedagógica na Educação Infantil traz consigo uma concepção de criança, sociedade, cultura, arte, conhecimento, processos de aprendizagem e desenvolvimento.

Compreendemos criança, infância e educação como categorias constituídas em processos históricos, sociais e culturais. Nessa direção os processos de aprendizagem e desenvolvimento das crianças pequenas e os conhecimentos construídos são estabelecidos em uma relação intrinsecamente associada aos processos gerais de constituição da criança, uma vez que toda e qualquer aprendizagem é consequência das relações que elas estabelecem com a realidade social e natural no âmbito de uma infância situada (ROCHA, 1999, 2001).

Com base em Barbosa e Horn (2008), defendemos uma concepção de prática pedagógica com as crianças de 0 a 5 anos de idade como construção de um território dialógico e democrático, no qual as crianças, desde as mais pequenas, devem ter voz e serem de fato escutadas nas suas cem linguagens, tendo, nesse caso, o professor como um parceiro sensível às suas necessidades ao compartilharem o mesmo contexto socioeducativo. Nessa concepção, a dimensão lúdica, as interações e as linguagens são fundamentais na constituição das práticas pedagógicas.

As reflexões anteriores encontram ressonância nas Diretrizes Curriculares Nacionais para a Educação Infantil (DCNEI) (BRASIL, 2010), por estas compreenderem e definirem que as práticas pedagógicas construídas e desenvolvidas nas creches e pré-escolas devem ter como eixos norteadores as interações e a brincadeira e, simultaneamente, favorecer a imersão das crianças de 0 a 5 anos de idade nas diferentes linguagens (e em seus vários gêneros), visando ao avanço sistemático por elas dos diversos modos de expressão, ou seja: plástica, dramática, musical e gestual (BRA-

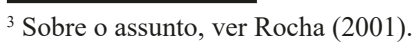


SIL, 2010, p. 25). Assim estruturadas, as práticas anunciadas nas DCNEI pretendem assegurar a construção de diferentes relacionamentos das crianças com a pluralidade de manifestações na área da “[...] música, artes plásticas e gráficas, cinema, fotografia, dança, teatro, poesia e literatura" (BRASIL, 2010, p. 26), dentro de um contexto de socialização, aprendizagem e desenvolvimento integral das crianças sustentado pela brincadeira e as interações (criança(s)-criança(s) e criança(s)-adulto(s)).

Benjamin (1984, 1995a, 1995b) e estudiosos de sua obra (SANTOS, 2015; PIRES, 2014; BARBOSA et al., 2013; SOUZA, 2009; AGAMBEN, 2008) nos ajudam a compreender e a sustentar um posicionamento no qual as linguagens são produzidas e produzem um campo complexo no qual é engendrada uma rede de relações entre conhecimento, linguagem e experiência, sendo estes associados aos processos culturais e sociais de onde emergem. Ou seja, a linguagem não é um instrumento simplista de abstração da realidade, mas de criação desta. Seguindo o pensamento benjaminiano, todas as expressões e manifestações humanas podem ser compreendidas como linguagem, sendo ela, por sua vez, apreendida na sua dimensão simbólica.

Nos escritos de Benjamin, encontramos a valorização da experiência dos jovens e crianças como potencial de conhecimento e sensibilidade, na contramão de um pensamento hierarquizado no qual a vida adulta seria, em si, a idade da experiência por excelência, na qual o erro é excluído (BENJAMIN, 1984, 1995a, 1995b). Segundo Pires (2014):

Os adultos, para Benjamin, gabam-se de sua experiência, a qual
é esvaziada de sentido quando, segundo o filósofo, restringe-se
à mera vivência individual (Erlebnis), em uma sucessão inter-
minável do mesmo, em um cotidiano petrificado. O vazio dessa
vivência individual é engendrado por uma ação que se limita a
si própria; a qual não faz outra coisa senão repetir a história e
reificar a ordem. Ela tende, na verdade, ao apagamento da ex-
periência que a precedeu. (PIRES, 2014, p. 818).

Benjamin chama a atenção para o fato de que a repetição - presente e intensa - na brincadeira das crianças não cai na abstração, no vazio que nos conduz sempre à mesmice de um cotidiano já estabelecido e vivido pelos adultos. Benjamin, apoiado em um pequeno verso de Goethe, afirma ser a repetição uma das características da brincadeira das crianças, a forma de estas terem e elaborarem suas experiências. Para o autor, “[...] a essência do brincar não é um 'fazer como se', mas um 'fazer sempre de novo'. Transformação da experiência mais comovente, em hábito” (BENJAMIN, 1984, p. 75), no qual a criança é capaz de saborear, repetidas vezes com revigorada intensidade, suas glórias e conquistas (BENJAMIN, 1984, p. 75). 
Partindo das reflexões anteriores, é possível estender a compreensão do brincar das crianças, na perspectiva benjaminiana, para as experiências infantis nas e com as linguagens da arte nas práticas pedagógicas na Educação Infantil. Falamos, então, da indispensável necessidade de as crianças terem possibilidades de experiências contínuas nas linguagens da arte, nas quais possam provar e serem provocadas expressiva e sensivelmente a saborear repetidamente suas conquistas e descobertas em um campo no qual barulhos, músicas, cores, texturas, formas animadas, gestos e movimentos corporais, imagens, etc. instituem e são instituídos em linguagens artísticas.

Estes são os pressupostos guias da nossa leitura dentro do contexto histórico, político, social, cultural e artístico no qual nos situamos. Com base nesses pressupostos questionamos: quais são as linhas conceituais ou guias teóricos da produção acadêmica voltada às relações entre as linguagens da arte e a educação das crianças pequenas nos trabalhos da Anped, no recorte temporal de 5 anos (2007-2011)?

\section{A PRODUÇÃO ACADÊMICA DA ANPED (2007-2011) SOBRE A EDUCAÇÃO DAS CRIANÇAS PEQUENAS E AS LINGUAGENS ARTÍSTICAS: INICIANDO A LEITURA}

No ano 2014, finalizamos uma pesquisa de cunho documental (CELLARD, 2012) tendo como objetivos principais o mapeamento e a interpretação qualitativa da produção acadêmica voltada à educação das crianças pequenas e as linguagens da arte nos trabalhos apresentados nas reuniões nacionais da Associação Nacional de Pós-Graduação e Pesquisa em Educação (Anped) entre os anos 2007 e 2011. Tal estudo visava à expansão das reflexões sobre as temáticas das pesquisas apresentadas, as bases teóricas nelas empregadas e suas possíveis implicações à prática pedagógica com as crianças de 0 a 3 anos de idade nas instituições de Educação Infantil.

Por que centrar a pesquisa nos trabalhos apresentados na Anped? De acordo com os estatutos dessa Associação, suas reuniões visam possibilitar a divulgação de investigações realizadas no Brasil no campo da Educação, especialmente entre pesquisadores, docentes e estudantes. Simultaneamente, buscam promover a discussão dos encaminhamentos teórico-metodológicos que sustentam tais pesquisas, os resultados por elas obtidos e suas implicações nas mais diversas dimensões do campo da educação e da pesquisa. Soma-se a esses objetivos o traço político distintivo da Anped e seus membros para com a defesa constante do direito de todos os cidadãos brasileiros à educação pública, gratuita e de qualidade. Assim, consideramos ser indispensável o diálogo com os trabalhos apresentados nessas reuniões, uma vez que 
estes acabam por revelar um panorama atual dos caminhos e reflexões acadêmicas referente à educação.

Para tanto, concentramo-nos no mapeamento dos trabalhos pertencentes a dois Grupos de Trabalho (GTs) que compõem a Anped, a saber: Educação de crianças de 0 a 6 anos (GT 07) e Educação e arte (GT 24). ${ }^{44}$ A definição por esses grupos considerou que, entre os 24 GTs que compõem a estrutura da Anped nacional, o GT 07 e o GT 24, de forma explícita, abordam pesquisas e reflexões referentes ao objetivo central da nossa investigação. O GT 07 foi criado dentro da Anped no ano 1981, tendo, assim, 25 anos a mais de existência em relação ao GT 24, que teve o início da sua implantação na referida Associação no ano 2007 como Grupo de Estudo (GE 01 Educação e arte). Para a definição do recorte temporal do mapeamento, consideramos o ano de criação do GT 24, deixando fora toda a produção do GT 07 anterior a essa data até o ano 2011, totalizando cinco anos de abrangência da nossa pesquisa para ambos os GTs.

O primeiro passo da pesquisa foi a captação on-line de todos os trabalhos disponibilizados na página das reuniões anuais da Anped referentes aos GTs 07 e 24 no período de 2007 a 2011. A partir da totalidade dos trabalhos de cada GT, definimos como um primeiro critério de seleção a busca por palavras-chave contidas nos títulos, resumos e/ou palavras-chave definidos pelos autores dos trabalhos. Entretanto, as palavras-chave empregadas nessa etapa foram diferenciadas para cada GT, considerando aqui a identidade de cada GT. Isso, porque todos os trabalhos apresentados no GT 07 estão voltados, de um modo ou de outro, à educação da infância, aos sujeitos com idades entre 0 a 5 anos. Assim, não fazia sentido ter como primeiro critério de seleção de trabalhos as palavras-chave: crianças/infância, bebês, crianças pequenas, Educação Infantil, e sim aquelas relacionadas às linguagens da arte. Entretanto, as palavras-chave: criança(s) e infância(s), bebês, crianças pequenas e Educação Infantil fazem todo sentido ao aparecerem como primeiro critério de seleção dos trabalhos do GT 24, uma vez que este abarca produções acadêmicas que trazem reflexões sobre arte da Educação Infantil à pós-graduação e mesmo fora desses contextos, como, por exemplo, a questão das pichações na cidade São Paulo na perspectiva da existência de uma "pedagogia fora da lei" (COELHO, 2009).

Na seleção dos trabalhos do GT 24 foram definidas as seguintes palavras-chave: 1) criança(s)/infância(s); Educação Infantil, creche, pré-escola; bebês, crianças pequenas, 0 a 3 anos de idade; 2) linguagem(ns) - música, dança, teatro,

\footnotetext{
${ }^{4}$ Sobre a trajetória histórica do Grupo de Trabalho Educação de Crianças de 0 a 6 anos (GT 07), ver Rocha (2008). Sobre a criação do Grupo de Trabalho Educação e Arte (GT 24), ver Anped (2015).
} 
artes visuais (desenho, pintura, modelagem/argila/barro, escultura/construção(ões) tridimensional(is), gravura, colagem(ns)). Para a seleção dos trabalhos no GT 07 consideramos as mesmas palavras-chave, porém ordenadas da seguinte forma: 1) $\operatorname{arte(s),~linguagem(ns)~-~música(s)/som(ns),~dança(s)/movimento/corpo,~teatro/ges-~}$ to/gestualidade, artes visuais (desenho, pintura, modelagem/argila/barro, escultura/ construção(ões) tridimensional(is), gravura, colagem(ns)); 2) bebês, crianças pequenas, 0 a 3 anos de idade.

De 2007 a 2011, o Comitê Científico do GT 24, Educação e Arte, da Anped selecionou um total de 92 trabalhos a serem apresentados (Quadro 1) nas reuniões. Realizamos, então, a primeira busca e seleção interna considerando as seguintes palavras-chave: criança(s), infância(s), sendo então localizados 17 trabalhos (Quadro 1). Com base nessa busca podemos dizer que pouco menos de $20 \%$ do total dos trabalhos apresentados no GT 24, ao longo de cinco anos, dizem respeito diretamente às questões da arte na educação da infância (0 a 12 anos de idade). Desse total, quantos abordam especificamente educação infantil, bebês, crianças pequenas, 0 a 3 anos de idade? Quais são as temáticas e linguagens que os constituem?

Quadro 1 - Seleção dos trabalhos apresentados no GT 24 (Educação e Arte) da Associação Nacional de Pós-Graduação e Pesquisa em Educação, entre os anos 2007 e 2011

\begin{tabular}{|l|r|}
\hline \multicolumn{1}{|c|}{ Critério de seleção } & \multicolumn{1}{|c|}{$\begin{array}{c}\text { Número de } \\
\text { trabalhos locali- } \\
\text { zados }\end{array}$} \\
\hline Total de trabalhos apresentados no GT 24 no período investigado & 92 \\
\hline $\begin{array}{l}\text { Trabalhos contendo as palavras-chave criança(s) e infância(s) em seus } \\
\text { títulos, resumos e/ou palavras-chave }\end{array}$ & 13 \\
\hline $\begin{array}{l}\text { Trabalhos contendo as palavras-chave criança(s) e infância(s) tratan- } \\
\text { do do Ensino Fundamental }\end{array}$ & \\
\hline $\begin{array}{l}\text { Trabalhos contendo as palavras-chave criança(s) e infância(s) tratan- } \\
\text { do da Educação Infantil }\end{array}$ & \\
\hline
\end{tabular}

Fonte: o autor.

A leitura dos textos completos revelou que dos 17 trabalhos selecionados, 13 tratavam de questões relacionadas à arte nas séries iniciais do Ensino Fundamental (Quadro 1) e somente quatro se referiam à Educação Infantil. Embora a presença de discussões do campo da arte no Ensino Fundamental, trazendo as dimensões da infância 
e do sujeito criança, seja positiva, por outro lado, revela a exígua produção de trabalhos apresentados no GT-24 sobre as linguagens da arte na Educação Infantil. E mais, nesse pequeno grupo de trabalhos, não havia um só relacionado diretamente com as especificidades da educação das crianças de 0 a 3 anos de idade, conforme Quadro 2.

Quadro 2 - Seleção dos trabalhos apresentados no GT 24 (Educação e Arte) da Associação Nacional de PósGraduação e Pesquisa em Educação, entre os anos 2007 e 2011, com foco na Educação Infantil

\begin{tabular}{|l|l|}
\hline \multicolumn{1}{|c|}{ Critério de seleção } & \multicolumn{1}{|c|}{$\begin{array}{c}\text { Número de } \\
\text { trabalhos locali- } \\
\text { zados }\end{array}$} \\
\hline $\begin{array}{l}\text { Trabalhos identificados contendo as palavras-chave criança(s), } \\
\text { infância(s) e arte }\end{array}$ & 4 \\
\hline $\begin{array}{l}\text { Trabalhos com foco na educação das crianças de 0 a } 3 \text { anos de idade } \\
\text { (creche) }\end{array}$ & \\
\hline $\begin{array}{l}\text { Trabalhos com foco na educação das crianças de } 4 \text { a } 6 \text { anos de idade } \\
\text { (pré-escola) }\end{array}$ & \\
\hline $\begin{array}{l}\text { Trabalhos com discussões da educação geral das crianças de 0 a } 6 \\
\text { anos de idade }\end{array}$ & \\
\hline Fonte: 0 autor. & \\
\hline
\end{tabular}

A leitura dos quatro trabalhos identificados como pesquisas com foco na educação das crianças no âmbito da Educação Infantil possibilitou identificar as seguintes temáticas de reflexão: práticas pedagógicas desenvolvidas em artes visuais (pedagogias em arte) realizadas com crianças em idade pré-escolar (4 a 5 anos) (CUNHA, 2007); a experiência poética e a linguagem plástica na infância (RICHTER, 2008); a linguagem da escultura na educação das crianças de 4 a 5 anos de idade (OLIVEIRA, 2009); a educação da criança e as músicas infantis (EISENBERG; CARVALHO, 2011) (Quadro 3). Assim, considerando o objetivo central da nossa pesquisa, sinalizamos a inexistência de uma produção voltada às especificidades da educação das crianças de 0 a 3 anos de idade no seu diálogo com as linguagens da arte neste GT. O trabalho de Eisenberg e Carvalho (2011), por exemplo, traz reflexões sobre a música na educação das crianças de 0 a 6 anos de idade a partir de uma revisão bibliográfica e de enquetes com professores desse nível da educação básica brasileira. Pouquíssimas são as reflexões e aprofundamentos teóricos sobre essa linguagem artística e a educação das crianças pequenas apresentadas no referido trabalho. 
Quadro 3 - Temáticas de pesquisa presentes nos quatro trabalhos apresentados GT 24 (Educação e Arte) da Associação Nacional de Pós-Graduação e Pesquisa em Educação entre 2007 e 2011

\begin{tabular}{|l|l|l|l|}
\hline \multicolumn{1}{|c|}{ Título do trabalho } & \multicolumn{1}{|c|}{ Autores } & Ano & \multicolumn{1}{|c|}{$\begin{array}{c}\text { Temática de } \\
\text { pesquisa }\end{array}$} \\
\hline $\begin{array}{l}\text { Entre Van Goghs, Monets e dese- } \\
\text { nhos mimeografados: pedagogias } \\
\text { em arte na Educação Infantil }\end{array}$ & CUNHA, Susana V. & 2007 & $\begin{array}{l}\text { Práticas pedagó- } \\
\text { gicas em artes } \\
\text { visuais com as } \\
\text { crianças na Edu- } \\
\text { cação Infantil }\end{array}$ \\
\hline $\begin{array}{l}\text { Experiência poética e a lingua- } \\
\text { gem plástica na infância }\end{array}$ & RICHTER, Sandra S. & 2007 & $\begin{array}{l}\text { Artes plásticas } \\
\text { na Educação } \\
\text { Infantil }\end{array}$ \\
\hline $\begin{array}{l}\text { Das águas onde nada um tubarão } \\
\text { às esculturas de gelo produzidas } \\
\text { por crianças no contexto da Edu- } \\
\text { cação Infantil }\end{array}$ & $\begin{array}{l}\text { OLIVEIRA, Alessandra } \\
\text { M. R. de }\end{array}$ & 2009 & $\begin{array}{l}\text { Artes plásticas } \\
\text { (escultura) } \\
\text { na Educação } \\
\text { Infantil }\end{array}$ \\
\hline $\begin{array}{l}\text { A educação das crianças e as } \\
\text { músicas infantis }\end{array}$ & $\begin{array}{l}\text { EISENBERG, Zena W. } \\
\text { I.; CARVALHO, Maria } \\
\text { C. M. P. de }\end{array}$ & 2011 & $\begin{array}{l}\text { Música na Edu- } \\
\text { cação Infantil }\end{array}$ \\
\hline
\end{tabular}

Fonte: o autor.

Em relação à produção do GT 07, nos cinco anos investigados, o Comitê Científico da Anped selecionou um total de 84 trabalhos a serem apresentados em suas reuniões anuais entre os anos 2007 e 2011, conforme Tabela 1. Como procedemos no mapeamento dos trabalhos do GT 24, buscamos, na totalidade dos trabalhos localizados, identificar em seus títulos, resumos e palavras-chave definidas pelos autores, aquelas de interesse de nossa pesquisa, ou seja: 1) arte(s), linguagem(ns) - música(s)/ $\operatorname{som}(\mathrm{ns})$, dança(s)/movimento/corpo, teatro/gesto/gestualidade, artes visuais (desenho, pintura, modelagem/argila/barro, escultura/construção(ões) tridimensional(is), gravura, colagem(ns). Assim, na primeira seleção, obtivemos um total de 20 trabalhos apresentados no GT 07 abordando a arte na Educação Infantil (de 0 a 5 anos de idade). 
Tabela 1 - Seleção dos trabalhos apresentados no GT 07 (Educação de crianças de 0 a 6 anos de idade) da Associação Nacional de Pós-Graduação e Pesquisa em Educação, entre os anos 2007 e 2011

\begin{tabular}{crr}
\hline Ano & N. de trabalhos & N. de trabalhos selecionados com base nas palavras-chave \\
\hline 2007 & 18 & 5 \\
2008 & 18 & 4 \\
2009 & 16 & 2 \\
2010 & 17 & 4 \\
2011 & 15 & 5 \\
Total & 84 & 20 \\
\hline Fonte: 0 autor. & &
\end{tabular}

Do montante de 20 trabalhos selecionados, após leitura cuidadosa, identificamos apenas quatro deles que abordavam a educação das crianças de 0 a 3 anos de idade, sendo eles assim intitulados: "No contexto da creche, o cuidado como ética e a potência dos bebês" (GUIMARÃES, 2008), "A Educação Infantil no contexto pós-reforma: instituições e regulação no Brasil e na Argentina" (CAMPOS, 2009), "A vida do bebê: a constituição de infâncias saudáveis e normais nos manuais de puericultura brasileiros" (SANTOS, 2010) e "Quero mais, por favor!: disciplina e autonomia na Educação Infantil” (NASCIMENTO, 2011), este último entrou na seleção por trabalhar com crianças de 3 e 4 anos de idade. Assim, podemos dizer que a leitura dos 20 trabalhos selecionados nessa etapa da pesquisa revelou que nenhum deles tratava diretamente da arte e suas linguagens na educação das crianças de 0 a 3 anos de idade.

O que pudemos constatar na leitura dos textos é que a seleção dos 20 trabalhos com as palavras-chave delimitadas incluiu, por exemplo, trabalhos que tinham em suas metodologias de pesquisa com crianças as linguagens da arte, como a investigação desenvolvida por Sobrinho (2008), que emprega - entre outros instrumentos - o desenho infantil. Outro fator que corroborou tal resultado foi a busca realizada com o grupo de palavras-chave "teatro/gesto/gestualidade", que, por exemplo, trouxe o trabalho intitulado: "Olhares, gestos e falas nas relações de adultos e crianças no cotidiano de escolas de Educação Infantil” (CORSINO; SANTOS, 2007). Uma pesquisa realizada com crianças de 4 a 6 anos de idade nos momentos de alimentação em oito instituições de Educação Infantil, compreendeu esse momento como uma "[...] estação de educação do corpo que, entre outras, emerge e compõe a rotina desses ambientes educacionais." (CORSINO; SANTOS, 2007, p. 1). Porém, mesmo trazendo palavras que também se fazem fortemente presentes no vocabulário da área do teatro (como gestos e olhares), ela não trata dessa linguagem artística na educação das crianças. 
Entre as quatro pesquisas que tratam das especificidades da educação dos bebês, destacamos aqui o trabalho de Guimarães (2008) por ser o único identificado no levantamento que realiza reflexões acerca da prática pedagógica com bebês e apresenta questões caras ao campo das artes e da estética. Segundo a investigação realizada por Guimarães (2008), o trabalho pedagógico com os bebês na creche se sobrepõe a uma perspectiva educacional ou ao cuidado na perspectiva ética " [...] tanto no ensino das competências orgânicas/culturais, tais como andar, comer, dormir, quanto na produção do que se denomina na creche de 'trabalhinhos'.” (GUIMARÃES, 2008, p. 10). Entenda-se aqui por "trabalhinhos" um "estilo de arte escolar", como bem define a pesquisadora da área da Arte-Educação Ana Mae Barbosa. Segundo Barbosa (2001):

[...] o estilo da arte escolar é o mesmo, tanto em escolas particulares quanto públicas, apesar do uso de material mais diversificado nas primeiras. As atividades são em geral centralizadas em trabalhos de ateliê e subordinadas ao mesmo uso pseudo-original de sucata, aos mesmos temas convencionais, aos mesmos símbolos culturais e comerciais (Natal, Dia das Mães etc.), à mesma relação, supostamente nova, entre expressão corporal e expressão pictórica ou expressão plástica e dramatização, usando exercícios semelhantes ou, ainda, subordinados à mesma relação superficial entre música e artes visuais, reduzida a uma suposta representação gráfica da música e dos sons. (BARBOSA, 2001, p. 34, grifo nosso).

Somam-se às reflexões de Barbosa (2001) a ideia e a forte presença da utilização de materiais para colorir, cobrir, ligar os pontos e modelos (moldes) a serem copiados, recortados e extraídos da internet com conteúdo como figuras geométricas, datas comemorativas, personagens infantis consagrados pela indústria cultural e voltados ao público infantil, assim como - na atual onda comercial dos livros para colorir - reproduções de obras de artistas mundialmente reconhecidos e que fazem parte dos “trabalhinhos". Considerando as reflexões de Guimarães (2008), os "trabalhinhos" marcam os primeiros contatos com as materialidades gráfico-plásticas das crianças pequenas. Um quadro que, infelizmente, aproxima-se daquele apontado na pesquisa realizada por Cunha (2007) - citada entre os trabalhos do GT 24 - e realizada com crianças com idades acima dos três anos. Há os que defendam que, exatamente por serem bebês, as crianças necessitam de propostas como estas para experimentarem as linguagens da arte, em um sentido muito diverso daquele da experiência proposto por Benjamin (1984, 1995a, 1995b). Sobre a questão, Barbosa (2001, p. 5) esclarece que a tipologia de exercícios tida como "trabalhinhos" compreende a arte como uma simples reprodução de formas e mais, "trata-se de um exercício de coordenação entre o olho e a mão. Deveria ser rejeitado, não por ter sido empregado no século XIX, 
mas porque lhe faltam validade científica e correspondência com a estética e as atuais reflexões advindas da arte contemporânea." (BARBOSA, 2001, p. 5). A esses argumentos acrescentaríamos, ainda, que propostas pedagógicas edificadas na concepção dos "trabalhinhos" negam a criança como sujeito capaz de autoria desde a mais tenra idade, destituindo-lhe o direito de expressão singular ou a criação de seu próprio estilo, pois conforme Ostrower (1987), é um modo de fazer único que somente aquele sujeito poderia fazer.

Segundo Guimarães (2008), a prática pedagógica no berçário por ela analisada segue a repetição de moldes. Também na pesquisa de Cunha (2007), apresentada no GT 24, a presença nefasta dos modelos e cópias foi identificada na educação das crianças maiores nos contextos de Educação Infantil. A pesquisa de Guimarães (2008) não apenas explicita a prática pedagógica instaurada pelos adultos no berçário, como ressalta o movimento das crianças pequenas diante do que lhes é proposto.

Percebo uma movimentação de agregar as crianças num canto, fazendo uma roda com elas. Michelle chega com um papel grande e coloca no meio. Pergunta, dirigindo-se a todo grupo, mas especialmente às companheiras: "vamos desenhar quem?". Pegam Adrian. Começam a fazer o contorno do menino no papel, enquanto os outros olham, vão na direção do menino, puxam a roupa delas... Depois, dizem "vamos pintar?" Colocam as crianças numa roda. Derrubam tinta no papel onde está desenhado o contorno do menino e convidam as crianças a espalharem com a mão. Michelle afirma "deixa sujar, depois vamos para o banho...". As crianças espalham a tinta, olham para si, para as mãos, para o papel de modo absorto [...] Uma hora depois, já na sala: enquanto Leila e Idjane arrumam as crianças nas cadeiras para o almoço, Michelle cola o boneco que pintaram no mural e começa a fazer olho, nariz e boca de papel para colar nele. É um momento de muita diversão entre elas. Parecem orgulhosas do boneco. (Caderno de campo, 02 de maio de 2006).

Os adultos transmitem técnicas - esperar, observar, aquietar o corpo e reproduzir modelos. Ao mesmo tempo, o olhar e o movimento das crianças organizam-se em outras direções. Enquanto uma das profissionais faz o molde do menino, um bebê descobre e explora a fita do avental dela. Depois, enquanto eles pintam o boneco, outros sentidos e direções surgem: exploram o espaço, batem na tinta, esfregando-a na barriga, na perna, nos braços. No interior do que é nomeado como "trabalhinho", as crianças criam movimentos/expressões, afetando-se mutuamente, buscando contato com objetos que estão disponíveis. (GUIMARÃES, 2008, p. 10-11). 
As análises dessa autora, pautadas no filósofo da linguagem Mikhail Bakhtin, indicam o quanto ainda temos que, como adultos, profissionais que atuam pedagogicamente com as crianças pequenas, construir um olhar capaz de reconhecer nas crianças com idades inferiores aos três anos "[...] atos cotidianos como criações estéticas." (GUIMARÃES, 2008, p. 11).

Assim, ao mesmo tempo que constatamos a ausência de trabalhos apresentados nos GTs 07 e 24 da Anped que abordem diretamente as linguagens da arte na educação das crianças de 0 a 3 anos de idade, é extremamente gratificante encontrarmos um trabalho que, tendo foco nas relações de cuidado das crianças pequenas como ética, traz ações desenvolvidas no cotidiano da prática pedagógica com os bebês nas quais as linguagens da arte se fazem presentes, como no caso da pintura (GUIMARÃES, 2008, p. 10-11).

\section{AMPLIANDO A LEITURA}

Com base nas reflexões tecidas até aqui, pontuamos a ausência de trabalhos que foquem diretamente as linguagens artísticas na educação das crianças de 0 a 3 anos de idade entre aqueles apresentados nas reuniões nacionais da Associação Nacional de Pós-Graduação e Pesquisa em Educação (Anped) no Grupo de Trabalho Educação e Arte (GT 24) e no Grupo de Trabalho Educação de Crianças de 0 a 6 anos (GT 07), no período 2007-2011. Tal resultado não somente denuncia um "silêncio" nos grupos citados, em relação às especificidades das linguagens da arte e a educação formal das crianças de 0 a 3 anos de idade, como aponta para o amplo campo investigativo que se apresenta para as áreas da arte e da Educação Infantil para, entre outros aspectos, contribuir na construção e no fortalecimento de práticas pedagógicas que ampliem as possibilidades de formação das crianças pequenas nas e com as linguagens artísticas.

O "silêncio" identificado, ao mesmo tempo que impossibilitou averiguar as questões iniciais propostas na pesquisa, resultou na elaboração de um conjunto de novas questões, na direção de alimentar outros estudos. Embora não tenhamos condições objetivas, neste momento, de respondê-las, consideramos importante registrá-las, pois expressam, de alguma forma, resultados da pesquisa realizada: teriam os comitês científicos do GT 24 e do GT 07 recebido a inscrição de trabalhos com o foco na arte e suas linguagens e na educação das crianças de 0 a 3 anos de idade, porém recusado por não atenderem aos critérios científicos estabelecidos pelos Comitês e a Anped? Em caso negativo e, havendo produções científicas com o foco requerido na nossa investigação, por que seus autores não os apresentam nas reuniões da Anped? 
Onde está sendo apresentada, divulgada a produção científica sobre as linguagens da arte e as crianças pequenas (os bebês)? Estaria tal produção nas associações científicas específicas de cada linguagem da arte, como na: Associação Nacional dos Pesquisadores em Artes Plásticas (Anpap), Congresso Nacional da Federação de Arte Educadores do Brasil (Confaeb), Associação Nacional de Pesquisadores em Dança (Anda), Associação Brasileira de Pesquisa e Pós-Graduação em Artes Cênicas (Abrace), Associação Nacional de Pesquisa e Pós-Graduação em Música (Anppom) e Associação Brasileira de Educação Musical (Abem)? Será que realmente não temos produzido sobre a prática pedagógica com os elementos da arte na Educação Infantil? No caso da existência de uma produção engendrada especificamente na área da Educação Infantil, em que eventos científicos ela estaria sendo divulgada? Ou seja: de fato, não temos uma produção acadêmica sobre a arte e suas linguagens na educação das crianças de 0 a 3 anos de idade, ou há e ela está sendo divulgada e discutida fora da Anped?

Ainda no contexto da Anped, não poderíamos deixar de pontuar as reflexões tecidas pela coordenadora do GT 24, Educação e Arte, a pesquisadora Márcia Strazzacappa, em um período posterior ao desenvolvimento da nossa pesquisa. Em 2015, em entrevista concedida ao Boletim da Anped, explicitou que, entre as inúmeras questões que necessitam de avanços neste GT, estavam as reflexões sobre a presença da arte na Educação Infantil, assim como a presença de disciplinas do campo da arte nos cursos de formação de professores, em especial, na Pedagogia. Sem dúvida, vemos aqui o reconhecimento deste GT para com o caminho a ser por ele trilhado e enfrentado no que se refere à tríade: arte, crianças, Educação Infantil. ${ }^{5}$ Os traços desse caminho em construção já podem ser visualizados quando, por ocasião da 36ª Reunião da Anped (2013), o referido GT trouxe como trabalho encomendado A presença da Arte nos cursos de formação de professores para a Educação Infantil e anos iniciais do Ensino Fundamental, elaborado e apresentado pela pesquisadora Miriam Celeste F. D. Martins. Na direção de colaborar para o enfrentamento da questão pontuada por Strazzacappa (2015), chamamos a atenção para que, nos esforços deste GT em abarcar de modo mais contundente as reflexões sobre o "ensino" da arte na primeira etapa da Educação Básica brasileira, as linguagens da arte na educação das crianças de 0 a 3 anos de idade não fiquem por demais diluídas, dispersas no imenso guarda-chuvas que é a Educação Infantil ou que tal preocupação não se restrinja, por parte dos pesquisadores que participam desse GT, à educação das crianças de 4 a 5 anos de idade. Nessa direção, intensificar os diálogos entre o GT 24 e 07 nas reuniões da Anped (em nível nacional e regional), parece-nos ser imprescindível, pois este úl-

\footnotetext{
${ }^{5}$ Informação disponível em: $36^{\mathrm{a}}$ Reunião... (2013).
} 
timo apresenta historicamente uma trajetória mais longa nas discussões com foco na educação da Educação Infantil - e nesta, sobre as crianças pequenas.

Em relação à produção acadêmica do GT 07, também não poderíamos deixar de mencionar o levantamento da produção deste mesmo GT - nas reuniões anuais - realizado por Gonçalvez et al. (2015), cobrindo um período de 10 anos (2003 a 2013). Tal pesquisa se propôs - a partir da análise de conteúdo - a identificar os percursos e tendências da produção científica sobre crianças com idades inferiores aos quatro anos nos trabalhos do GT 07. A pesquisa apresentada por Gonçalvez et al. (2015) localizou um total de 23 trabalhos, em 10 anos, tratando especificamente da educação das crianças pequenas. A partir da análise desse conjunto, as autoras citadas nos apresentam um panorama com quatro grandes temáticas nas quais os trabalhos são agrupados, a saber: dimensão pedagógica, perspectivas sociológicas, políticas para a Educação Infantil e história (GONÇALVEZ et al., 2015, p. 12). De acordo com Gonçalvez et al. (2015), a maior incidência ocorreu na temática da dimensão pedagógica, com 17 de trabalhos, seguida da temática perspectivas sociológicas, com quatro. Entre as questões acercadas pelas pesquisas, estão as “[...] especificidades da docência com bebês, organização dos espaços e tempo; ampliação das reflexões sobre o cuidado, linguagem, literatura, relações com as famílias, relações étnico-raciais, inserção e crianças atendidas no meio rural.” (GONÇALVEZ et al., 2015, p. 14).

Mesmo com um espectro temporal e temático muito mais amplo do que aquele por nós investigado na mesma fonte de pesquisa, os resultados apresentados por Gonçalvez et al. (2015) reafirmam o "silêncio" por nós identificado no que se refere às relações entre as linguagens artísticas e a educação das crianças pequenas na produção acadêmica da Anped GT 07. E, se por um lado as pesquisadoras são otimistas em relação à expansão das pesquisas que trazem como foco a educação das crianças pequenas (GONÇALVEZ et al., 2015, p. 14) no referido GT, de outro alertam para a necessidade da construção de investigações que tragam para a discussão temáticas pertinentes às linguagens da arte na educação das crianças de 0 a 3 anos de idade.

\section{CONSIDERAÇÕES FINAIS}

O "silêncio" em relação às linguagens da arte na educação das crianças de 0 a 3 anos de idade na produção acadêmica do Grupo de Trabalho Educação e Arte (GT 24) e do Grupo de Trabalho Educação de Crianças de 0 a 6 anos (GT 07) entre 2007 e 2011 - e, no caso do GT 07, até 2013, considerando a pesquisa de Gonçalvez et al. (2015) -, não podemos indicar, conforme previmos nos objetivos do estudo, as 
contribuições teórico-metodológicas presentes no campo da Educação na interface com a arte, como a princípio imaginávamos.

Em um País em que atualmente enfrentamos as grandes incertezas no campo da política educacional em relação à garantia de acesso e permanência das crianças pequenas nas instituições públicas e de gestão pública, a luta contra um "padrão de educação básico" (FERREIRA, 2016, p. 9), que não prima pela qualidade do serviço oferecido, o quadro encontrado neste estudo, infelizmente, pouco colabora para a inversão desse "padrão".

Por fim, pesquisas no campo da Educação voltadas às linguagens artísticas e às crianças de 0 a 3 anos de idade no âmbito das instituições de Educação Infantil - mas não a elas restritas - são necessárias e urgentes! É indispensável investirmos em pesquisas de cunho teórico, documental, com a participação ativa das crianças pequenas e/ou sobre práticas pedagógicas e ações cotidianas engendradas nas relações entre crianças-arte-adultos, a fim de podermos identificar limites e, simultaneamente, enfrentarmos o desafio (da prática pedagógica e acadêmica) que consiste na complexidade de fazer valer as cem linguagens das crianças no cotidiano das instituições de Educação Infantil. Ampliar a rede de diálogo do campo da Educação com aqueles específicos da arte, por exemplo, pode ajudar a ampliar nossa compreensão sobre a arte na educação das crianças pequenas e as possibilidades de construção e diversificação das práticas pedagógicas com essas crianças, assegurando a elas uma educação pública e de gestão pública de qualidade.

\section{REFERÊNCIAS}

36a REUNIÃO nacional da Anped. Trabalhos encomendados. Goiânia, 2013. Disponível em: <http://36reuniao.anped.org.br/trabalhos-encomendados $>$. Acesso em: 15 abr. 2015.

AGAMBEN, G. Infância e história: destruição da experiência e origem da história. Belo Horizonte: Ed. UFMGF, 2008.

ANPED. GT24 - Educação e Arte. Disponível em: < http://www.anped.org.br/ grupos-de-trabalho/gt24-educa $\% \mathrm{C} 3 \% \mathrm{~A} 7 \% \mathrm{C} 3 \% \mathrm{~A} 3 \mathrm{o}-\mathrm{e}-$-arte $>$. Acesso em: 25 mar. 2015.

BARBOSA, A. M. John Dewey e o ensino da arte no Brasil. São Paulo: Cortez, 2001. 
BARBOSA, I. G. Prática Pedagógica na Educação Infantil. In: OLIVEIRA, D. A. et al. (Org.). Dicionário: trabalho, profissão e condição docente. Belo Horizonte: Ed. UFMG/Faculdade de Educação, 2010a.

BARBOSA, M. C. S. et al. Linguagens e crianças: tecendo uma rede pela educação da infância. RevistAleph, Niterói, n. 19, p. 5-23, jul. 2013. Disponível em: <http:// revistaleph.uff.br/index.php/REVISTALEPH/article/view/381>. Acesso em: 25 mar. 2015.

BARBOSA, M. C. S.; HORN, M. G. S. Projetos pedagógicos na Educação Infantil. Porto Alegre: Artmed, 2008.

BARBOSA, M. C. S. Pedagogia da infância. In: OLIVEIRA, D. A. et al. (Org.). Dicionário: trabalho, profissão e condição docente. Belo Horizonte: Ed. UFMG/Faculdade de Educação, 2010b. 1 CD-ROM.

BARBOSA, M. C. S. et al. Linguagens e crianças: tecendo uma rede pela educação da infância. RevistAleph, Niterói, n. 19, p. 5-23, jul. 2013. Disponível em: <http:// revistaleph.uff.br/index.php/REVISTALEPH/article/view/381>. Acesso em: 25 mar. 2015.

BENJAMIN, W. A criança, o brinquedo e a educação. São Paulo: Summus, 1984.

BENJAMIN, W. Magia e técnica, arte e política. Obras escolhidas I. São Paulo: Brasiliense, 1995a.

BENJAMIN, W. Rua de mão única. Obras escolhidas II. São Paulo: Brasiliense, 1995b.

BRASIL. Emenda Constitucional n. 59, de 11 de novembro de 2009. Disponível em: <http://www.planalto.gov.br/ccivil_03/constituicao/Emendas/Emc/emc59.htm>. Acesso em: 22 mar. 2010.

BRASIL. Ministério da Educação. Secretaria de Educação Básica. Diretrizes curriculares nacionais para a Educação Infantil. Secretaria de Educação Básica. Brasília, DF: MEC, SEB, 2010.

CALDEIRA, A. M. S.; ZAIDAN, S. Práxis pedagógica: um desafio cotidiano. Paidéia, Belo Horizonte, ano 10, n. 14, p. 15-32, jan./jun. 2013. Disponível em: <http:// www.fumec.br/revistas/paideia/article/view/2374>. Acesso em: 07 abr. 2015.

CAMPOS, R. F. A Educação Infantil no contexto pós-reforma: institucionalização e regulação no Brasil e na Argentina. In: REUNIÃO ANUAL DA ANPED, 32., 2009, Caxambu. Anais... Caxambu, 2009. Disponível em: <http://32reuniao.anped.org.br/ arquivos/trabalhos/GT07-5895--Int.pdf>. Acesso em: 25 abr. 2012. 
CELLARD, A. A análise documental. In: POUPART, J. et al. (Org.). A pesquisa qualitativa: enfoques epistemológicos e metodológicos. Petrópolis: Vozes, 2012. p. 295-316.

COELHO, G. Pichações na metrópole: uma pedagogia fora da lei. In: REUNIÃO ANUAL DA ANPED, 32., 2009, Caxambu. Anais... Caxambu, 2009. Disponível em: <http://32reuniao.anped.org.br/arquivos/trabalhos/GT24-5832--Int.pdf >. Acesso em: 28 abr. 2012.

CORSARO, W. A. A reprodução interpretativa no brincar ao faz de conta das crianças. Educação, Sociedade \& Culturas, Porto, n. 17, p. 113-134, 2002.

CORSINO, P.; SANTOS, N. O. Olhares, gestos e falas nas relações de adultos e crianças no cotidiano de escolas de Educação Infantil. In: REUNIÃO ANUAL DA ANPED, 30., 2007, Caxambu. Anais... Caxambu, 2007. Disponível em: $<$ http://30reuniao.anped.org.br/trabalhos/GT07-3448--Int.pdf>. Acesso em: 25 abr. 2012.

COUTINHO, A. M. S. A ação social dos bebês: um estudo etnográfico no contexto da creche. Tese (Doutorado em Estudos da Criança, Especialidade em Sociologia da Infância)-Universidade do Minho, Portugal, 2010.

CUNHA, S. V. Entre Van Goghs, Monets e desenhos mimeografados: pedagogias em artes na educação infantil. In: REUNIÃO ANUAL DA ANPED, 30., 2008, Caxambu. Anais... Caxambu, 2008. Disponível em: <http://30reuniao.anped.org.br/ grupo_estudos/GE01-3033--Int.pdf>. Acesso em: 25 abr. 2012.

EISENBERG, Z. W.; CARVALHO, M. C. M. P. A educação das crianças e as músicas infantis. In: REUNIÃO ANUAL DA ANPED, 34., 2008, Natal. Anais... Natal, 2008. Disponível em: <http://34reuniao.anped.org.br/images/trabalhos/GT24/GT2436\%20int.pdf $>$. Acesso em: 25 abr. 2012.

FARIA, A. L. G.; MELLO, S. A. Territórios da infância: linguagem, tempos e relações para uma pedagogia para as crianças pequenas. Araraquara: Junqueira e Marin, 2009.

FERREIRA, V. S. A expansão da Educação Infantil e suas prováveis implicações. In: REUNIÃO CIENTÍFICA REGIONAL DA ANPED-SUL, 11., 2016, Curitiba. Anais... Curitiba, 2016. Disponível em: <http://www.Anpedsul2016.ufpr.br/wp-content/uploads/2015/11/Eixo-5-Educa $\%$ C3\%A7\%C3\%A3o-e-Inf $\%$ C3\%A2ncia. pdf>. Acesso em: 08 ago. 2016.

FOCCHI, P. "Mas o que os bebês fazem no berçário, hein?": documentando as ações de comunicação, autonomia e saber-fazer de crianças de 6 a 14 meses em contextos de vida coletiva. Dissertação (Mestrado em Educação)-Universidade Federal do Rio Grande do Sul, Porto Alegre, 2013. 
GOBBI, M. A.; PINAZZA, M. A. (Org.). Linguagens infantis: convite à leitura. In: GOBBI, M. A.; PINAZZA, M. A. (Org.). Infância e suas linguagens. São Paulo: Cortez, 2014. p. 11-19.

GONÇALVEZ, F. et al. Percursos e tendências da produção científica sobre crianças de 0 a 3 anos na Anped. In: REUNIÃO ANUAL DA ANPED-SUL, 10., 2015, Florianópolis. Anais... Florianópolis, 2015. Disponível em: $<$ http://xanpedsul.faed. udesc.br/arq pdf/1238-0.pdf>. Acesso em: 10 nov. 2014.

GUIMARÃES, D. O. No contexto da creche, o cuidado como ética e a potência dos bebês. In: REUNIÃO ANUAL DA ANPED, 13., 2008, Caxambu. Anais... Caxambu, 2008. Disponível em: <http://31 reuniao.anped.org.br/1trabalho/GT07-4807--Int. pdf>. Acesso em: 25 abr. 2012.

\section{LA BARACCA - TESTONI RAGAZZI. Carta dei diritti dei bambini all'arte e} alla cultura. Bologna: Edizioni Pendragon, 2011.

NAÇÕES UNIDAS. Convenção sobre os direitos da criança. Washington: Nações Unidas, 1989. Disponível em: <http://www.onu-brasil.org.br/doc_crianca.php>. Acesso em: 10 set. 2010.

NASCIMENTO, A. M. do. "Quero mais, por favor!”: disciplina e autonomia na Educação Infantil. In: REUNIÃO ANUAL DA ANPED, 34., 2008, Natal. Anais... Natal, 2008. Disponível em: <http://34reuniao.anped.org.br/images/trabalhos/GT07/ GT07-770\%20int.pdf> Acesso em: 25 abr. 2012.

OLIVEIRA, A. M. R. de. Das águas onde nada um tubarão às esculturas de gelo produzidas por crianças no contexto da Educação Infantil. In: REUNIÃO ANUAL DA ANPED, 31., 2008, Caxambu. Anais... Caxambu, 2008. Disponível em: $<$ http://32reuniao.anped.org.br/arquivos/trabalhos/GT24-5419--Int.pdf > . Acesso em: 25 abr. 2012.

OSTROWER, F. Criatividade e processos de criação. Petrópolis: Vozes, 1987.

PIRES, E. G. Experiência e linguagem em Walter Benjamin. Educação e Pesquisa, São Paulo, v. 40, n. 3, p. 813-828, jul./set. 2014.

RICHTER, S. S. Experiência poética e linguagem plástica na infância. In: REUNIÃO ANUAL DA ANPED, 30., 2008, Caxambu. Anais... Caxambu, 2008. Disponível em: <http://30reuniao.anped.org.br/grupo_estudos/GE01-3538--Int.pdf>. Acesso em: 25 abr. 2012. 
ROCHA, E. A. C. 30 anos da Educação Infantil na Anped: caminhos da pesquisa. Zero a Seis, Florianópolis, v. 1, n. 17, p. 52-65, jan./jun. 2008. Disponível em: $<$ https://periodicos.ufsc.br/index.php/zeroseis/issue/view/959>. Acesso em: 12 mar. 2013.

ROCHA, E. A. C. A Pedagogia e a Educação Infantil. Revista Brasileira de Educação, Rio de Janeiro, n. 16, p. 27-34, jan./abr. 2001. Disponível em: <http://www. scielo.br/pdf/rbedu/n16/n16a03.pdf>. Acesso em: 15 abr. 2006.

ROCHA, E. A. C. A pesquisa em Educação Infantil no Brasil: trajetória recente e perspectiva de consolidação de uma pedagogia da Educação Infantil. Florianópolis: NUP, 1999.

SANTOS, C. A. A vida do bebê: a constituição de infâncias saudáveis e normais nos manuais de puericultura brasileiros. In: REUNIÃO ANUAL DA ANPED, 33., 2010, Caxambu. Anais... Caxambu, 2010. Disponível em: <http://33reuniao.anped.org.br/ internas/ver/trabalhos-gt07>. Acesso em: 25 abr. 2012.

SANTOS, S. V. S dos. Walter Benjamin e a experiência infantil: contribuições para a educação infantil. Pro-Posições, v. 26, n. 2, p. 223-239, maio./ago. 2015.

SARMENTO, M. J. As culturas da infância nas encruzilhadas da Segunda Modernidade. In: CERISARA, A. B.; SARMENTO, M. J. (Org.) Crianças e miúdos: perspectivas sociopedagógicas da infância e educação. Porto: Asa Editores, 2004. p. 9-34.

SCHMITT, R. "Mas eu não falo a língua deles!": as relações sociais de bebês em creche. Dissertação (Mestrado em Educação)-Universidade Federal de Santa Catarina, Florianópolis, 2008.

SOARES, M. B. As pesquisas nas áreas específicas influenciando o curso de formação de professores. In: ANDRÉ, M. (Org.). O papel da pesquisa na formação e na prática dos professores. Campinas: Papirus, 2001. p. 91-105.

SOBRINHO, R. S. M. "Pra fazer a farinhada... Muita gente eu chamar": contextos lúdicos e as culturas das crianças sateré-mawé. In: REUNIÃO ANUAL DA ANPED, 33., 2008, Caxambu. Anais... Caxambu, 2007. Disponível em: <http://31 reuniao. anped.org.br/1trabalho/GT07-4345--Int.pdf>. Acesso em: 25 abr. 2012.

SOUZA, S. J. Walter Benjamin e a infância da linguagem: uma teoria crítica da cultura e do conhecimento. In: SOUZA, S. J.; KRAMER, S. (Org.). Política, cidade e educação: itinerários de Walter Benjamin. Rio de Janeiro: Contraponto, 2009. p. 185-204. 
STACCIOLI, G. Diário de acolhimento na escola da infância. Campinas: Autores Associados, 2013.

TRISTÃO, F. C. Ser professoras de bebês: um estudo de caso em uma creche conveniada. Dissertação (Mestrado em Educação)-Universidade Federal de Santa Catarina,. Florianópolis, 2004.

Recebido em: 19 de dezembro de 2016 Aceito em: 14 de fevereiro de 2017

Endereço para correspondência: Trindade, 88040-900, Florianópolis, Santa Catarina, Brasil; alessandra.rotta.oliveira@ufsc.br 
